\title{
Sentinel Lymph Node Biopsy in Vulvar Cancer: What is the Standard of Care?
}

\section{Lindsey Beffa and Katina Robison*}

Program in Women's Oncology, Department of Obstetrics and Gynecology, Women and Infants Hospital, Alpert Medical School, Brown University, USA

\begin{abstract}
Purpose: The surgical treatment of most vulvar cancers includes a lymph node evaluation. Historically, inguinofemoral lymphadenectomy was performed with significant associated morbidity. Sentinel lymph node biopsy has been studied as an alternative in order to decrease postoperative morbidity. This review summarizes the evidence supporting the use of sentinel lymph node biopsy as standard of care in vulvar cancer.

Findings: Sentinel lymph node biopsy has a sensitivity of $92 \%$ with a negative predictive value of $97-98 \%$. Combining both radiotracer and dye methods improves the sentinel lymph node detection rate and sensitivity. The rate of groin recurrence and 5-year overall survival are comparable to inguinofemoral lymphadenectomy. Postoperative complications including lymphedema, wound infection and wound separation are significantly lower after sentinel lymph node biopsy.

Summary: Sentinel lymph node biopsy for the surgical evaluation of vulvar cancer is feasible, cost-effective, associated with less short- and long-term morbidity when compared to inguinofemoral lymphadenectomy and has comparable rates of survival and groin recurrence. Sentinel lymph node biopsy should be performed as the standard of care for appropriate patients in high-volume centers.
\end{abstract}

Keywords: Vulvar cancer; Sentinel lymph node; Gynecologic malignancies

\section{Introduction}

Vulvar cancer remains an uncommon disease comprising approximately $4 \%$ of gynecologic malignancies, with an estimated 6020 new vulvar cancer cases and 1150 vulvar cancer deaths predicted in the United States in 2017 [1]. Surgical resection remains the mainstay of vulvar cancer staging; however, the surgical management strategies have evolved with time. Historically a radical vulvectomy with en-bloc inguinofemoral lymphadenectomy was performed but with significant associated morbidity [2]. The triple incision technique demonstrated less morbidity with comparable survival outcomes and became the standard of care [3]. Sentinel lymph node biopsy, using similar techniques to melanoma and breast cancer surgical lymph node evaluation, is now acceptable and preferable in appropriate patients to decrease morbidity associated with inguinofemoral lymphadenectomy [4].

\section{Vulvar Cancer}

Lymph node metastases are the most significant prognostic factor in vulvar squamous cell carcinoma (SCC) demonstrating the continued importance of regional lymph node evaluation at the time of surgical staging [5]. Survival directly correlates with lymph node positivity: patients with negative inguinal lymph nodes have a 5 year survival rate of $96 \%$, compared to $80 \%$ in patients with up to two positive lymph nodes and $12 \%$ in those with greater than two positive lymph nodes [6]. Complications are seen in the majority of patients who undergo radical vulvectomy with en-bloc inguinofemoral lymphadenectomy. Early complications including wound infection, wound breakdown or necrosis occur in up to $85 \%$ of patients and late complications including lower extremity lymphedema occur in up to $70 \%$ of patients [7].

The transition to a triple-incision technique in the 1980s was in effort to decrease morbidity associated with radical vulvectomy with enbloc inguinofemoral lymphadenectomy while preserving the survival rates associated with radical surgical excision. While complication rates decreased with this technique, they continued to be significant. Using separate incisions to perform a radical vulvectomy and inguinofemoral lymphadenectomy, wound complication rates of $17-40 \%$ are seen for wound breakdown, wound infection, and lymphocyst formation. The rate of lymphedema also remains significant with up to $30 \%$ of patients suffering from this late, and potentially permanent, complication. One review demonstrated that $76 \%$ of patients had at least one postoperative complication [8]. While imperative to appropriate treatment planning and staging, the degree of lymphadenectomy required during surgical evaluation has come under debate.

The likelihood of groin metastasis is low in early stage vulvar cancer patients, specifically $10-15 \%$ of patients with lesions $<20 \mathrm{~mm}$ will have lymph node metastases $[9,10]$. Unfortunately clinical examination of groin nodes is inaccurate, with a false negative rate up to $24 \%$; proving the importance of continued lymph node sampling at the time of surgery [11]. Sentinel lymph node biopsy was introduced for vulvar cancer patients in order to evaluate groin lymph nodes while decreasing surgical morbidity, as the majority of patients with early stage vulvar cancer will have negative lymph nodes [5].

\section{Sentinel Lymph Node Biopsy}

Initially described in penile cancer in the 1970s, sentinel lymph node biopsy has been used in other cancer types for decades in order

*Corresponding author: Katina Robison, MD, Program in Women's Oncology, Department of Obstetrics and Gynecology Women and Infants Hospital, Brown University, Providence, RI, USA, Tel: +011-401-274-1100; Fax: +011-401-453-7529; E-mail: krobison@wihri.org

Received August 12, 2017; Accepted August 31, 2017; Published September 07, 2017

Citation: Beffa L, Robison K (2017) Sentinel Lymph Node Biopsy in Vulvar Cancer What is the Standard of Care? J Oncol Transl Res 3: 118. doi: 10.4172/24762261.1000118

Copyright: @ 2017 Beffa L, et al. This is an open-access article distributed under the terms of the Creative Commons Attribution License, which permits unrestricted use, distribution, and reproduction in any medium, provided the original author and source are credited. 
to identify patients who may require additional lymph node dissection [12]. Sentinel lymph node biopsy became the standard of care in the treatment of melanoma and breast cancer in the 1990s [13,14]. DiSaia et al. described sentinel nodes in vulvar cancer in the late 1970s, being inguinal nodes above the cribriform fascia. It was noted that if these superficial lymph nodes were free of metastatic disease, the risk of identifying positive deep groin or pelvic lymph nodes was low [15]. Levenback et al. [16] initially described the feasibility of performing sentinel lymph node biopsy in vulvar cancer in 1994 and since that time multiple additional studies have been conducted to confirm the feasibility of this technique [17-22].

Sentinel lymph node dissection uses the concepts that within a regional lymph node basin, there is a consistent and orderly pattern to lymphatic drainage and that the first lymph node(s) act as a filter for migrating tumor cells [23]. Therefore, if the sentinel lymph node(s) is negative, the remainder of the lymph nodes within that lymph node basin should be negative. Dissecting fewer lymph nodes for accurate evaluation of lymph nodes metastases is one of the greatest benefits of sentinel lymph node biopsy. Different techniques for performing sentinel lymph node biopsy have been studied including injection of radioactive tracer technetium-99 $\mathrm{m}$ sulfur colloid (Tc-99 m) and injection of blue dye. Pathologic assessment of sentinel lymph nodes should involve ultra-staging and staining with hematoxylin and eosin (H\&E) [24].

A meta-analysis performed by Hassanzade et al. [25] reviewed 49 studies that used blue dye, radiotracer, or both mapping methods and confirmed that sentinel lymph node dissection was an appropriate and accurate technique to surgically evaluate groin lymph nodes in the treatment of vulvar cancer. Pooled detection rates for sentinel lymph node per patient were $94.4 \%$ and per groin was $84.6 \%$. Pooled sensitivity per patient and groin were each $92 \%$ with $8 \%$ false negative rates. The pooled negative predictive values were $97 \%$ per patient and $98 \%$ per groin. This meta-analysis identified that mapping method impacted the detection and sensitivity of sentinel lymph nodes and concluded that combining radiotracer and blue dye methods yields the highest detection rates and sensitivity. Midline tumors were found to have higher false negative results compared to lateral tumors; and those patients with palpable inguinal lymph nodes had lower sensitivity and detection rates [25].

The GROningen INternational Study on Sentinel nodes in Vulvar cancer (GROINSS-V) included patients with unifocal vulvar cancer measuring less than $4 \mathrm{~cm}$ and allowed those with negative sentinel lymph node to be followed, while those with positive sentinel lymph nodes then underwent inguinofemoral lymphadenopathy. The study design of GROINSS-V differed from prior studies in that many of previous studies performed sentinel lymph node biopsy followed by inguinofemoral lymphadenopathy to determine the negative predictive value of sentinel lymph node dissection [26]. This study demonstrated that patients with negative sentinel lymph nodes had low rates of groin recurrence, minimal morbidity from the sentinel lymph node procedure and excellent survival [27].

The rate of groin recurrence following sentinel lymph node biopsy has been evaluated as groin recurrences are correlated with high mortality rates. The groin recurrence rate following superficial inguinofemoral lymphadenopathy has been reported at 5-7\% [2830]. The GROningen INternational Study of Sentinel nodes in Vulvar cancer (GROINSS-V-I) reported a groin recurrence rate of $2.9 \%$ [27]. Additional studies have confirmed low rates of groin recurrence following sentinel lymph node biopsy alone, including Robison et al. who reported a groin recurrence rate per patient of $5.2 \%$ following sentinel lymph node biopsy alone [31-35]. A population-based analysis

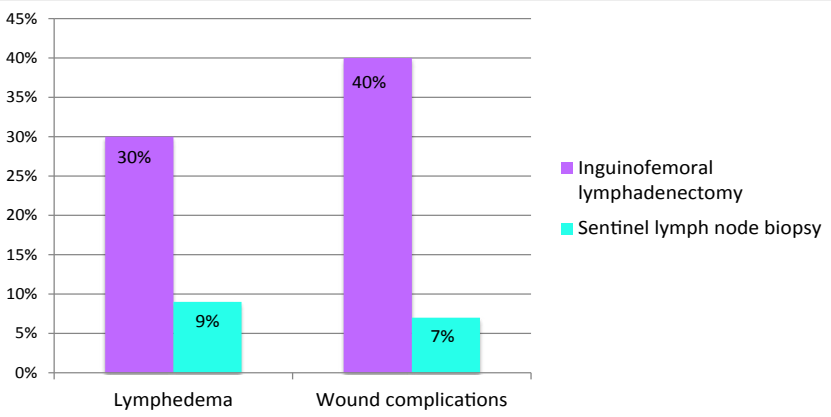

Figure 1: Complication rates based on lymph node dissection approach $[8,27,31]$

performed by Rottman et al. reported that despite an increase in the use of sentinel lymph node biopsy over a 16 year period from $11.4 \%$ to $39.1 \%$, there was no change in local recurrence (19\%), lymph node recurrence (9\%) or 5 year overall survival (55\%) [36]. This data suggests that patients treated with sentinel lymph node biopsy alone will have similar risk of groin recurrence and no change in overall survival.

Postoperative complications were also lower with sentinel lymph node biopsy compared to inguinofemoral lymph node dissection, depicted in Figure 1. In patients treated with sentinel lymph node biopsy alone, lymphedema has been reported between $2-9 \%$ and $7 \%$ of patients had wound complications including wound infection, lymphocyst or wound separation [27,31]. Additionally, sentinel lymph node biopsy has been associated with an improvement in quality of life [36].

Studies evaluating the cost effectiveness of sentinel lymph node biopsy for vulvar cancer have shown that compared to inguinofemoral lymphadenectomy, sentinel lymph node biopsy has decreased cost, in addition to being associated with decreased length of hospital stay [37]. Sentinel lymph node biopsy became an alternative standard of care procedure presented in the National Comprehensive Cancer Network vulvar cancer treatment guidelines [38]. It is currently recommended that sentinel lymph node biopsy be performed by a high-volume surgeon as some studies have suggested improved detection rates based on surgeon experience performing sentinel lymph node biopsy $[26,27]$. The GROINSSV-II study only allowed enrollment at centers experienced in sentinel lymph node biopsy and will help to answer the question regarding the appropriate management of positive sentinel lymph nodes. The management of positive sentinel lymph nodes is currently under debate, but may include adjuvant radiation with or without inguinofemoral lymphadenectomy. GROINSS$\mathrm{V}$-II is evaluating recurrence rates in patients with positive sentinel node metastasis $<2 \mathrm{~mm}$ and treating these patients with radiation while omitting inguinofemoral lymphadenectomy $[31,39,40]$. The results of GROINSSV-II will hopefully help to determine the best treatment course for these patients.

\section{Conclusion}

Numerous studies have demonstrated the benefit of sentinel lymph node biopsy in the surgical treatment of vulvar cancer. In centers with experienced surgeons, sentinel lymph node biopsy should be considered standard of care and an alternative to inguinofemoral lymphadenectomy in patients with negative clinical groin examination and unifocal tumor measuring $<4 \mathrm{~cm}$. To increase the sentinel lymph node detection rate and sensitivity, both radiocolloid and dye are recommended for mapping. If the primary tumor is $2 \mathrm{~cm}$ or greater from the midline, a unilateral sentinel lymph node biopsy is appropriate. For 
Citation: Beffa L, Robison K (2017) Sentinel Lymph Node Biopsy in Vulvar Cancer: What is the Standard of Care? J Oncol Transl Res 3: 118. doi: 10.4172/2476-2261.1000118

Page 3 of 3

a primary tumor within $2 \mathrm{~cm}$ of the midline, a bilateral sentinel lymph node biopsy is recommended. In the event that a sentinel node is not identified, inguinofemoral lymphadenectomy is recommended [26,38]. Sentinel lymph node biopsy is feasible, cost-effective and associated with decreased morbidity and wound complications; all while showing no negative impact on groin recurrence or survival.

\section{Conflict of Interest}

The authors have no conflict of interest.

\section{References}

1. https://www.cancer.org

2. Wills A, Obermair A (2013) A review of complications associated with the surgical treatment of vulvar cancer. Gynecol Oncol 131: 467-479.

3. Hopkins MP, Reid GC, Morley GW (1993) Radical vulvectomy. The decision for the incision. Cancer 72: 799-803.

4. Covens A, Vella E, Kennedy E, Reade C, Jimenez W, et al. (2015) Sentine lymph node biopsy in vulvar cancer: Systematic review, meta-analysis and guideline recommendations. Gynecol Oncol 137: 351-361.

5. Hacker N, Berek J, Lagasse L, Leuchter R, Moore JG (1983) Management of regional lymph nodes and their prognostic influence in vulvar cancer. Obstetr Gynecol 61: 408-412.

6. Robison K, Holman LL, Moore RG (2011) Update on sentinel lymph node evaluation in gynecologic malignancies. Curr Opin Obstet Gynecol 23: 8-12.

7. Podratz KC, Symmonds RE, Taylor WF, Williams TJ (1983) Carcinoma of the vulva: Analysis of treatment and survival. Obstet Gynecol 61: 63-74.

8. Gaarenstroom K, Kenter G, Trimbos J, Agous I, Amant F, et al. (2003) Postoperative complications after vulvectomy and inguinofemoral lymphadenectomy using separate groin incisions. Int J Gynecol Cancer 13: 522-527.

9. Homesely H, Bundy B, Sedlis A, Yordan E, Berek J, et al. (1991) Assessment of current International Federation of Gynecology and Obstetrics staging of vulvar carcinoma relative to prognostic factors for survival (a Gynecologic Oncology Group study). Am J Obstetr Gynecol 164: 997-1003.

10. Sedlis A, Homesley H, Bundy B, Marshall R, Yordan E, et al. (1987) Positive groin lymph nodes in superficial squamous cell vulvar cancer. A Gynecologic Oncology Group study. Am J Obstetr Gynecol 156: 1159-1164.

11. Homesley H, Bundy B, Sedlis A, Yordan E, Berek J, et al. (1993) Prognostic factors for groin node metastasis in squamous cell carcinoma of the vulva (a Gynecologic Oncology Group study). Gynecol Oncol 49: 279-283.

12. Cabanas RM (1977) An approach for the treatment of penile carcinoma Cancer 39: 456-466.

13. Morton D, Wen D, Wong J, Economou J, Cagle L, et al. (1992) Technical details of intraoperative lymphatic mapping for early stage melanoma. Arch Surg 127 392-399.

14. Cox CE, Pendas S, Cox JM, Joseph E, Shons AR, et al. (1998) Guidelines for sentinel node biopsy and lymphatic mapping of patients with breast cancer. Ann Surg 227: 645-651.

15. DiSaia P, Creasman W, Rich W (1979) An alternate approach to early cancer of the vulva. Am J Obstetr Gynecol 133: 825-832.

16. Levenback C, Burke T, Gershenson D, Morris M, Malpica A, et al. (1994) Intraoperative lymphatic mapping for vulvar cancer. Obstetr Gynecol 84: 163-167.

17. Ansink A, Sie-Go D, van der Velden J, Sijmons E, de Barros Lopes A, et al. (1999) Identification of sentinel lymph nodes in vulvar carcinoma patients with the aid of a patent blue $V$ injection. Cancer 86: 652-656.

18. De Cicco C, Sideri M, Bartolomei M, Grana C, Cremonesi M, et al. (2000) Sentinel node biopsy in early vulvar cancer. Br J Cancer 82: 295-299.

19. de Hullu JA, Hollema H, Piers DA, Verheijen RH, van Diest PJ, et al. (2000) Sentinel lymph node procedure is highly accurate in squamous cell carcinoma of the vulva. J Clin Oncol 18: 2811-2816.

20. Levenback C, Coleman R, Burke T, Bodurka-Bevers D, Wolf J, et al. (2001) Intraoperative lymphatic mapping and sentinel node identification with blue dye in patients with vulvar cancer. Gynecol Oncol 83: 276-281.
21. Moore R, DePasquale S, Steinhoff M, Gajewski W, Steller M, et al. (2003) Sentinel node identification and the ability to detect metastatic tumor to inguinal lymph nodes in squamous cell cancer of the vulva. Gynecol Oncol 89: 475-479.

22. Sliutz G, Reinthaller A, Lantzsch T, Mende T, Sinzinger H, et al. (2002) Lymphatic mapping of sentinel nodes in early vulvar cancer. Gynecol Oncol 84: 449-452.

23. Tanis PJ, Nieweg OE, Valdés Olmos RA, Th Rutgers EJ, Kroon BB (2001) History of sentinel node and validation of the technique. Breast Cancer Res 3: 109-112.

24. Moore R, Granai C, Gajewski W, Gordinier M, Steinhoff M (2003) Pathologic evaluation of inguinal sentinel nodes in vulvar cancer patients: a comparison of immunohistochemical staining versus ultra-staging with hematoxylin and eosin staining. Gynecol Oncol 88: 190.

25. Hassanzade M, Attaran M, Treglia G, Yousefi Z, Sadeghi R (2013) Lymphatic mapping and sentinel node biopsy in squamous cell carcinoma of the vulva: Systematic review and meta-analysis of the literature. Gynecol Oncol 130: 237245

26. Levenback C, Ali S, Coleman R, Gold M, Folwer J, et al. (2012) Lymphatic mapping and sentinel lymph node biopsy in women with squamous cell carcinoma of the vulva: A gynecologic oncology group study. J Clin Oncol 31: 3786-3791.

27. Van der Zee AG, Oonk MH, De Hullu JA, Ansink AC, Vergote I, et al. (2008) Sentinel node dissection is safe in the treatment of early-stage vulvar cancer. J Clin Oncol 26: 884-889.

28. Stehman F, Bundy B, Dvoretsky P, Creasman W (1992) Early stage I carcinoma of the vulva treated with ipsilateral superficial inguinal lymphadenectomy and modified radical hemivulvectomy: A prospective study of the gynecologic oncology group. Obstetr Gynecol 79: 490-497.

29. Burke T, Levenback C, Coleman R, Morris M, Silva E, et al. (1995) Surgica therapy of T1 and T2 vulvar carcinoma: Further experience with radical wide excision and selective inguinal lymphadenectomy. Gynecol Oncol 57: 215-220.

30. Stehman F, Bundy B, Ball H, Clarke-Pearson D (1996) Sites of failure and times to failure in carcinoma of the vulva treated conservatively: A gynecologic oncology group study. Am J Obstetr Gynecol 174: 1128-1132.

31. Robison K, Roque D, McCourt C, Stuckey A, DiSilvestro P, et al. (2014) Longterm follow-up of vulvar cancer patients evaluated with sentinel lymph node biopsy alone. Gynecol Oncol 133: 416-420.

32. Moore RG, Robison K, Brown AK, DiSilvestro P, Steinhoff M, et al. (2008) Isolated sentinel lymph node dissection with conservative management in patients with squamous cell carcinoma of the vulva: A prospective trial. Gynecol Oncol 109: 65-70.

33. Oonk MH1, van de Nieuwenhof HP, de Hullu JA, van der Zee AG (2009) The role of sentinel node biopsy in gynecological cancer: A review. Curr Opin Oncol 21: 425-432.

34. Levenback C, van der Zee A, Rob L, Plante M, Covens A, et al. (2008) Sentine lymph node biopsy in patients with gynecologic cancers expert panel statement from the International Sentinel Node Society Meeting. Gynecol Oncol 114: 151 156

35. Terada KY1, Shimizu DM, Jiang CS, Wong JH (2006) Outcomes for patients with T1 squamous cell cancer of the vulva undergoing sentinel node biopsy. Gynecol Oncol 102: 200-203.

36. Rottmann M, Beck T, Burges A, Dannecker C, Kiechle M, et al. (2016) Trends in surgery and outcomes of squamous cell vulvar cancer patients over a 16 yea period (1998-2013): A population-based analysis. J Cancer Res Clin Oncol 142: $1331-1341$

37. Cham S, Chen L, Burke WM, Hou JY, Tergas AI, et al. (2016) Utilization and outcomes of sentinel lymph node biopsy for vulvar cancer. Obstet Gynecol 128 754-760.

38. Greer BE, Koh WJ (2016) New NCCN Guidelines for vulvar cancer. J Nat Compr Canc Netw 14: 656-658.

39. Kole M, Robison K (2016) Sentinel lymph node evaluation in vulvar cancer: The new standard of care. J Cancer Clin Trials 1: 115.

40. Glaser S, Olawaiye A, Huang M, Beriwal S (2014) Inguinal nodal region radiotherapy for vulvar cancer: are we missing the target again? Gynecol Oncol 135: 583-585. 